\title{
Tool use in profoundly retarded humans: A method of subgrouping
}

\author{
CHARLES C. CLELAND and WILLIAM V. RAGO, JR. \\ University of Texas, Austin, Texas 78712 \\ and \\ AJIT MUKHERJEE \\ Corpus Christi State School, Corpus Christi, Texas 78408
}

\begin{abstract}
Tool using among profoundly mentally retarded (IQ $r=1-19$ ) is described as a method of delineating functional subtypes within this narrow intellectual range. Four cases of tool using and problem solving are presented, illustrative of how naturalistic observation of spontaneous tool using can complement intelligence testing in extracting more from less trainable persons in the lowest functioning human group. Although tool use rarely occurs at this level, its presence suggests an improved method for further training via imitation learning.
\end{abstract}

The evolutionary milestones augmenting the emergence of Homo sapiens include bipedal locomotion, tool usage, increased brain size, and speech (Washburn $\&$ Avis, 1958). Of these, tool use has been noted in chimpanzees, orangutans, gorillas, and sea otters (Rensch, 1972; Sebeok, 1967). As Gallup, Boren, Gagliardi, and Wallnau (1977) indicated, tool use was one of the "first candidates for a uniquely human trait," until it became evident that other species also used tools. The next "uniquely human" aspect of tool behavior, that is, man being the only animal to make tools, also evaporated as chimpanzees demonstrated this ability (Teleki, 1974). However, the claim that man is the only animal that uses tools to make tools remains uniquely human.

When tool use is considered in the profoundly mentally retarded human (PMR), whose mental age at adulthood rarely exceeds 3 years, whose IQ range is from 1 to 19 , and recognizable speech is almost universally absent (Grossman, 1977), a research lacuna is evident. This is so because at this low level of functioning, workers and researchers alike are bound by what Karl Duncker termed "functional fixedness." Who would expect on the basis of IQ alone (Brooks \& Baumeister, 1971) that PMRs would exhibit tool use behavior or spontaneous problem solving? Despite the PMRs' numerical rarity, "they stand on the threshold between man and not-man, and thus permit simultaneous inquiry into both the nature of man and the nature of culture-bearing animals" (MacAndrew \& Edgerton, 1964).

Wilson's (1975) concern for a careful definition of tool use led him to recommend Alcock's definition. Alcock (1972) defines tool usage as the "manipulation of an inanimate object, not internally manufactured, with the effect of improving the animal's efficiency in altering the position or form of some separate object."
Rumbaugh (1970), working from a definition similar to Alcock's, believes that tool use "is quite generally believed to reflect, at least in primates, some extraordinary capacity." And Reynolds (1967), investigating tool usage in young apes, remarks, "without teaching or example if materials are available," sticks or other objects will be employed as tools and weapons. If a necessary precondition for novel tool usage is the availability of manipulable materials, then the institutionalized PMR are unduly penalized. Institutional supervision mandates a primary concern for the residents' safety. As such, their inability to speak and unpredictable behaviors with regard to aggression (Cleland \& Clark, 1966; Rago, 1976) means their environment is notably lacking in objects that could be employed as tools or weapons. Thus, the presence of tool usage or problemsolving behavior in the PMR is as extraordinary a discovery as the presence of similar behavior in Rumbaugh's primates.

Our interest is to report on the utilization of tools among institutionalized (captive) profoundly retarded persons. It is believed that a concern for direct naturalistic observation of the PMR provides a perspective for uncovering spontaneously intelligent behavior that would go unsuspected if one simply focused upon their psychometrically measured intelligence quotients. This is Brooks and Baumeister's (1977) point when they urge researchers in mental retardation to be concerned with ecological validity. It is postulated that direct observation of spontaneous tool usage in the PMR population may provide a methodological procedure capable of delineating functional subtypes. This information would then play a valuable role in identifying candidates for a more intensive intervention program directed at developing the residents' latent skills.

All cases reported were identified through direct 
naturalistic observation of the subjects in their institutional environment. Observations were made by the authors, who totaled over $200 \mathrm{~h}$ in the field. The case studies reported were observed fortuitously, which not only. indicates the spontaneity that characterized the observed behavior but also illustrates the limitations contained within psychometric procedures when applied to the PMR.

\section{CASE OF TOOL USAGE}

\section{Case A: Date of Birth (DOB) 1-20-1944}

\section{Social Age (SA) $=3.7$, Social Quotient $(S Q)=15$}

Mas, a dwarfed male, approached me with a stick about $8 \mathrm{~cm}$ in length, which he rather vigorously employed in slapping his open-palmed hand. As he did so, a broad smile crossed his face. At about a $1.5 \mathrm{~m}$ distance from me, he held the stick out for me to take. Once accepted, Mas took my hand in his and proceeded to move my hand up and down to slap his open palm. When I spontaneously continued to slap his palm with the stick, Mas no longer directed my activity but merely smiled in delight. When I added music by humming "Yankee-Doodle" and slapped in keeping with the musical beat, his delight greatly intensified. On ceasing, his facial expression assumed dejection and he grabbed my hand and again motorically instructed me in the fundamentals of "his game." This activity so amused Mas that he persisted long after I wearied.

On another occasion, when a highly desired object was sighted but was beyond Mas's reach, he ran and attempted to drag a heavy steel outdoor bench under the object [the analogy to Köhler's (1925) chimpanzees on the box problems is evident]. The use of the bench as a tool would credit at the 8- to 9-year level on the Vineland Social Maturity Scale (Doll, 1953).

\section{Case B: DOB, 2-15-1944}

$\mathrm{SA}=3.8, \mathrm{SQ}=16$

Jane has resided in a state school for the last 16 years. It had long been known by the dormitory staff that Jane possessed a passion for coffee. Yet the strength of this incentive was a mystery until one afternoon when Jane was observed to perform the following behaviors.

The dormitory kitchen was always locked when not in service. Immediately above the door, however, was an open transom. On this particular day there happened to be several large $(1.2 \mathrm{~m}$ high) boxes in the hallway, away from the kitchen door, awaiting removal. Jane came by, saw the boxes, and immediately shoved one hard against the kitchen door. In the next moment she climbed onto the box, pushing against the door as she balanced herself; her hand pushed against the transom, which in its unlocked position could be seen to wobble. She immediately climbed through the opening, fell to the kitchen floor, and by the time the attendant was notified and the door unlocked, Jane was eating coffee.

Case C: DOB, 1-4-1948

$\mathrm{SA}=2.2, \mathrm{SQ}=10$

Joe, a semi-ambulatory institutionalized person, displayed the ability to employ his wheelchair as a tool. After being taught to retrieve cokes from a machine by insertion of a quarter, this became Joe's favorite activity. Ultimately, as chance would have it, the quarter lodged and no coke appeared. Joe instantly backed his wheelchair away, rolled it forward, rapidly hitting the machine, and repeated this until the machine activated.

Case D: DOB, 3-14-1963

$\mathrm{SA}=1.89, \mathrm{SQ}=15$

At chronological age (CA) 15, John is an avid television fan and manifests channel preferences. To obtain his favorite pro- grams was difficult due to ceiling mounting of the TV. John spontaneously employed stacking-type dayroom chairs to gain access to the TV and currently continues this practice to obtain his desired goal.

\section{DISCUSSION}

Space precludes giving more than a sample of the tool use cases actually noted, but in each of the above cases Alcock's (1972) criteria for tool use is clearly met. Our most intelligent subject's social quotient was 16 , our least intelligent subject had a social quotient of 10 . Despite the absence of manipulable objects, when the incentive strength reached the level of addiction (coffe, tobacco, cokes, and TV), our subjects displayed insightful Gestalt-like learning and tool use.

Forty-seven years have elapsed since Aldrich and Doll (1931) attempted Köhler's (1925) stick and box problems with idiots, although only two of their eight subjects' IQs fell within the profoundly retarded range. They concluded that idiot (now termed PMR) abilities lie between those of apes and those of normal infants. However, on the basis of work at Texas and Kansas with subjects (adolescent and adult) whose IQ range was between 1 and 19, they were unable to compete with chimpanzees on bent-wire problems (Hollis, 1962), were inferior to babies, champanzees, and monkeys on the visual cliff task (Garcia, Cleland, Rago, Wayne, \& Swartz, 1974), and in all studies to date were incapable of self-recognition (Harris, 1974). Nevertheless, within the extremely narrow psychometric range of 1 to 19 , individual differences exist, as our tool users demonstrate. These cases of spontaneous tool use are, in the authors' 39 years experience with PMRs, quite rare-an estimated $5 \%$ of their number being capable of tool using.

Despite the rarity of tool using, we are continuing to authenticate and document such cases. Although imitation learning is not a strength of the PMR, it does occur. Further, imitation learning in both chimpanzees and humans is augmented if the model is dominant or high status. By delineating PMR tool users who are also high in dominance, we propose to assemble five or more and systematically introduce singly low-dominant nontool users in an effort to determine if such skills can be imparted to nontool users, thus enhancing their limited behavioral repertoires. For, as Wilson (1975) suggests, evolutionary and comparative information on tool use is valuable and "Each scrap of information on this subject obtained in future field and laboratory studies, however loosely connected to previous information, should be regarded as potentially important" (p. 175). The methodological procedure of direct naturalistic observation of the profoundly retarded in their natural (institutional) settings is believed to be a means of discovering intelligent behavior that would not be attributed to the individuals on the basis of psychometric measures alone. The utilization of this naturalistic 
information may then be made operational through subgrouping differentiations.

\section{REFERENCES}

Alcock, J. The evolution of the use of tools by feeding animals. Evolution, 1972, 26, 464:473.

Aldrich, C. G., \& Doll, E. A. Problem-solving among idiots: The use of implements. Journal of Social Psychology, 1931, 2, 306-334.

Brooks, P. H., \& Baumeister, A. A. A plea for consideration of ecological validity in the experimental psychology of mental retardation: A .guest editorial. American Journal of Mental Deficiency, 1977, 81, 407-416.

Cleland, C. C., \& Clark, C. M. Sensory deprivation and aberrant behavior among idiots. American Journal of Mental Deficiency, 1966, 71, 213-225.

DofF, E. A. The measurement of social competence: $A$ manual for the Vineland Social Maturity Scale. Minneapolis, Minn: Educational Testing Bureau, 1953.

Gallup, G. G., Boren, J. L., Gagliardi, G., \& Wallnau, L. A mirror for the mind of man, or will the chimpanzee create an identity crisis for Homo sapiens? Journal of Human Evolution, 1977, 7.

Garcia, R., Cleland, C. C., Rago, W., Wayne, P., \& Swartz, J. Perception of depth in the profoundly retarded. Bulletin of the Psychonomic Society, 1974, 4, 185-187.

Grossman, H. J. (Ed.). Manual on terminology and classification in mental retardation. Washington, D.C: American Association on Mental Deficiency, 1977.

HARRIS, L. Self-recognition among institutionalized profoundly retarded males after extended mirror training. Unpublished masters thesis, University of Texas, Austin, 1974.
Hollis, J. Solution of bent-wire problems by severely retarded children. American Journal of Mental Deficiency, 1962, 67, 463-472.

KOHLER, W. The mentality of apes. New York: Harcourt Brace, 1925.

MACANDREw, C., \& Edgerton, R. The everyday life of institutionalized "idiots." Human Organization, 1964, 23, 312-318.

RAGO, W. V. Territoriality in the profoundly mentally retarded. In C. C. Cleland, J. D. Swartz, \& L. W. Talkington (Eds.), The profoundly mentally retarded. Austin, Tex: Western Research Conference and The Hogg Foundation, 1976.

RENSCH, B. Homo sapiens. New York: Columbia University Press, 1972.

REYNolds, V. The apes. New York: Dutton, 1967.

Rumbaugh, D. M. Learning skills of anthropoids. In L. Rosenblum (Ed.), Primate behavior (Vol. 1). New York: Academic Press, 1970.

SEBEOK, T. A. Discussion of communication processes. In S. Altman (Ed.), Social communication among primates. Chicago: University of Chicago Press, 1967.

TELEKI, G. Chimpanzee subsistence technology-materials and skills. Journal of Human Evolution, 1974, 3, 575-594.

WASHBURN, S. L., \& Avis, V. Evolution of human behavior. In A. Roe \& G. G. Simpson (Eds.), Behavior and evolution. New Haven: Yale University Press, 1958.

Wilson, E. O. Sociobiology: The new synthesis. Cambridge, Mass: Belknap Press of Harvard University Press, 1975.

(Received for publication April 18, 1978.) 